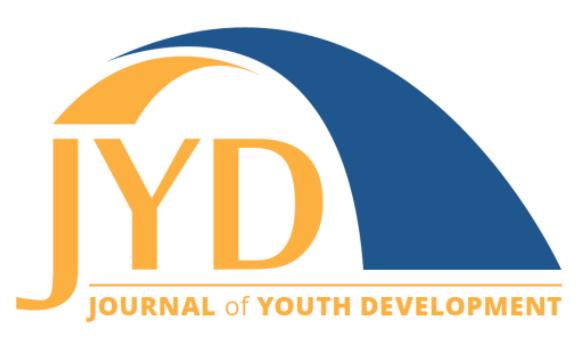

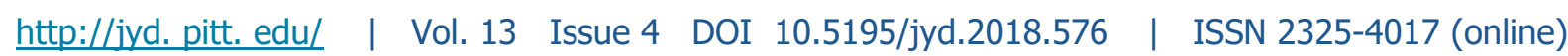

\title{
Campus Immersion: Supporting Youth Agency and Aspirations for Higher Education
}

\author{
Joanna A. Tzenis \\ University of Minnesota \\ tzeni004@umn.edu
}

\begin{abstract}
Encouraging aspirations for higher education among young people who are marginalized is a common youth program strategy for addressing educational and social disparities. However, data on educational attainment suggests that these aspirations often go unfulfilled and that there is a need for a different approach-one that more deeply considers the ways in which social context influences youth agency. Within this paper, I show that while marginalized youth have aspirations for higher education, they have fewer opportunities to take action to achieve them. Conceptually, this paper draws from Bourdieu's concept of "habitus" and Sen's capability approach in order to understand the aspirations for higher education among marginalized youth and how they can be supported through youth programs. A case from an overnight, campus-based youth program highlights how youth programs can support youths' agentic abilities to achieve their aspirations. The findings from this study suggest that both futureplanning activities and emulating student life prepared youth to navigate socio-cultural barriers to aspiration achievement. The presented findings offer insight into the nature of aspiring and have implications for how youth programs can be designed to effectively support agency and aspiration development among youth who have been marginalized.
\end{abstract}

Key words: agency, aspirations, youth program outcomes, higher education, capability approach, positive youth development

\section{Introduction}

Many young people aspire to go to college, but there is a gap between their aspirations and actual enrollment (Roderick, Nagaoka, \& Coca, 2009). This gap incites inquiry into the disconnection between aspirations and achievement. This paper reports findings from a qualitative case study that sought to understand the impact a short-term "campus immersion"

(cc) EY New articles in this journal are licensed under a Creative Commons Attribution 4.0 License. This journal is published by the University Library System, University of Pittsburgh and is cosponsored by the University of Pittsburgh Press. The Journal of Youth Development is the official peer-reviewed publication of the National Association of Extension 4-H Agents and the National AfterSchool Association. 
Supporting Youth Aspirations for Higher Education

youth program had on youths' aspiration development and agency. Specifically, it answers the question, "In what ways does a youth program that immerses young people in college life help youth be agentic and achieve their aspirations for higher education?"

\section{Marginalization, Education, and Future Well-Being}

Education can provide a pathway for youth to improve their lives by broadening their freedoms to participate in society and by equipping them with the skills they need to build their livelihoods through workforce participation (UNESCO, 2011). In societies around the world, the number of years in education is a key factor determining whether or not a person will be able to improve the quality of her life (UNESCO, 2010).

In the United States there exist great disparities in educational attainment among different groups of young people based on class, race, and ethnicity. Data on educational attainment reveal that youth from lower income families have a lower educational attainment rate than those in higher income families. Evidence also suggests that educational attainment is lower among racial and ethnic minority groups (U.S. Department of Education, 2014). While college enrollment rates have increased for all races in recent years, racial and ethnic minority college undergraduate students on average enroll at less academically selective institutions than their White counterparts (Fry, 2010).

The critical issue of educational disparities in the United States has not been ignored. In the past decade, there has been an influx of youth programs focused on science, technology, engineering, and math (STEM). STEM-focused youth programs are a response to the employment vacancies in STEM fields (Eberle, 2010). Programs often focus on providing young people with STEM skills and encouraging them to complete education past high school. Marginalized youth (i.e. young people who are excluded from social opportunities that could help them thrive or improve their lives) are frequently the target audience for such programs, as they would most benefit from improved educational outcomes and resulting career opportunities (DeJaeghere \& Lee, 2011; UNESCO, 2010). The assumption in this approach is that if a young person has the skills and the desire to pursue a STEM field, then she is equipped to act do so. And yet, while there is research suggesting that the number of individuals who aspire to attend higher education has increased across racial, ethnic, and income groups, STEM positions are not being filled, particularly by low-income and youth in racial minority groups (Roderick et al., 2009). More broadly, the gap in educational attainment among different groups of young people has not decreased (U.S. Department of Education, 2014). This disparity 
Supporting Youth Aspirations for Higher Education

suggests that skill development matched with boosted aspirations is not a sufficient strategy for addressing marginalization through education. Because lower educational attainment is affiliated with social disadvantage, youth programs aimed at improving the educational wellbeing of youth must recognize and address underlying social conditions-such as family income; dispositions toward education; and experiences based on racial, ethnic, or religious identification-that can help or constrain youths' abilities to overcome social disadvantage through education (DeJaeghere \& Lee, 2011). There is a need for a different approach that considers the role youth agency has in enabling youth to transform skills and desires into actual achievement by relying on social supports and overcoming social barriers (DeJaeghere, 2018; Gale \& Parker, 2015).

Many researchers who have studied future orientation or aspirations and youth development (e.g., Conradie \& Robeyns, 2013; DeJaeghere, 2018; Gale \& Parker, 2015; Walker, 2016) suggest that one reason educational disparities persist is that while the possession of aspirations indicates that an individual might hope for a particular future, that person might still have doubts about whether or not she is able to achieve these aspirations because of social norms and expectations associated with her identity. For example, low-income youth are often encouraged to pursue a trade school education, or women of color rarely see their identities represented in the field of engineering. In an effort to address constraining social norms and intentionally extend educational opportunities to groups of young people who experience marginalization, the University of Minnesota Extension Center for Youth Development designed a youth program to prepare youth for college that stretches beyond the provision of skill development and abstract aspiration encouragement. The program aims to help youth begin to imagine futures for themselves that include higher education, and begin to take the steps (i.e. enact agency) to achieve these aspirations through campus immersion and critical pedagogy.

This study had practical and empirical aims. This paper specifically reports on effective and replicable program design elements of the Minnesota Urban 4-H campus immersion program. It also seeks to contribute to the field by offering a deeper understanding of marginalized youths' agency and aspirations as they relate to higher education. It draws on DeJaeghere's (2018) conceptualization of aspirations, which she defines as what young people hope and imagine their lives to be like in the future and on McLeod's (2012) conceptualization of agency, which she defines as a young person's ability to take action toward a desired future. 


\section{Theoretical Framework}

\section{Youth Habitus: How Marginalization Affects Aspirations and Agency}

This study was guided by the theoretical framing of Bourdieu's $(1977,1990)$ concept habitus. Habitus refers to socialized disposition that guides people's actions based on what future they believe is within their reach (Bourdieu, 1990). It is often used to demonstrate how social structures constrain a person's abilities to achieve aspirations-revealing obstacles that are not conspicuous or immediately recognizable because they are internalized. For example, Bourdieu would argue that youths who grow up in a working class family will set themselves on a path (often subconsciously) to attain working class jobs, because that is what they believe is attainable (even if they desire a different future).

However, for this study, I relied on a feminist interpretation of habitus, which insists that one's deeply ingrained habits, behaviors, skills, and knowledge can be changed when a person is faced with adversity or new opportunities-a process Bourdieu (1990) referred to as reflexivity (McLeod, 2005). When a person is reflexive, she recognizes marginalizing social conditions and is better prepared to change them or circumvent them. This framework is helpful in highlighting social conditions in which aspirations are imagined and it shows there is opportunity to support youths' abilities to navigate constraining social arrangements. It is limited, however, in its ability to examine youth agency as a future-oriented process.

\section{The Capability Approach: Understanding Future-Oriented Action}

The capability approach (Sen, 1999) complements Bourdieu's work and examines the set of opportunities (i.e. capabilities) an individual has to use resources and to act (i.e. exercise agency) to achieve aspirations (Sen, 1999; Unterhalter, Vaughan \& Walker, 2007). The capability approach recognizes that an individual's freedoms to exercise her abilities to achieve functionings (Sen's term for achievements) differ depending on aspects of social identity like gender or ethnicity. However, Sen never theorizes agency as situated within constraining power structures (Alkire, 2005). For this reason, I blend these two frameworks-habitus and capability approach-to understand how a campus immersion program can support youth agency and aspirations for higher education. 
Supporting Youth Aspirations for Higher Education

\section{Youth Programs' Role in Addressing Inequalities}

Youth programs, as DeJaeghere (2018) points out, are often the sites of critical pedagogy and have the potential to be what Walker (2016) refers to as "opportunity-making space(s)" (p. 7) for youth to develop the critical thinking skills, develop a social network, and reimagine what is possible for them. This matters because as Gale and Parker (2015) indicate, young people from marginalized backgrounds are likely to aspire to an ultimate goal, such as being a doctor, but because of their social exclusion, lack the knowledge of the links between aspirations and aspiration achievement. Youth programs can play a role in helping youth gain experiences that help them shape their expectations of the future. This article will offer practical program model elements that help maximize this potential of youth programs to support youth as they try to change their lives through higher education.

Youth work practices that shape aspirations (such as those discussed in the findings section) are disproportionately critical for middle school-aged youth. Kao and Tienda (1998) found that middle school-aged "minority youth" tended to have optimistic, yet abstract aspirations because "the reality of college completion is so distant in time" (p. 356). However, as they reached high school, this optimism tempered as an increased awareness of structural obstacles made this desired future seem less attainable; their habitus was discordant with the future desires. Further, Balfanz (2009) found that it is in middle school, not high school, when young people veer off the college pathway. His findings suggest that poor grades, attendance, and test scores in middle school lead youth to disengage from their education and this pattern continues in high school. This research calls for more efforts to engage middle school youth.

Youth programs have the potential to help youth engage in social critique and prompt them to enact agency in a way that changes their social arrangements in order to achieve aspirations. The middle school years are a prime time to engage youth in such programs because they are at a developmental stage in their life when they are more inclined to have optimistic, yet abstract aspirations. It is also a time "of change in self-concept" as youth are inclined to try to understand themselves and their future possibilities in relation to social settings outside of their family (National Research Council, 2002, p. 57). 


\section{The Research Study}

\section{Program Description}

Youth participants in this study came from four youth program sites called Urban 4-H STEM clubs. These youth programs were supported by a federally funded grant allocated by the Children, Youth, and Families at Risk (CYFAR) program. Youth were recruited to the Minnesota Urban 4-H STEM programs by community partners who identified the participants as young people who faced educational barriers. One community organization was a Somali youth-serving organization whose mission is to keep Somali youth engaged in higher education and help them avoid negative influences to which they are vulnerable. This organization supports three youth programs included in this study. The other youth program took place in a middle school that serves one of the most economically divested parts of the Minneapolis-Saint Paul (Twin Cities) metropolitan area and has been identified by the state department of education as being in the bottom $10 \%$ of schools struggling with the achievement gap. All youth program participants spent 9 months in their after-school programs focusing on engineering design and leadership development. They then participated in an overnight campus immersion program that took place at the University of Minnesota Twin Cities campus during the summer. This paper focuses only on the youths' experience in the campus immersion program.

As part of the campus immersion experience, participants spent 4 days and 3 nights on the University of Minnesota campus. Youth stayed overnight in campus dormitories, ate in the campus cafeteria, engaged in STEM-related activities with faculty members, participated in activities about planning their futures, worked with college-age counselors, and showcased their learning at a family showcase event.

\section{Youth Participants}

In August 2015, 22 youth (14 males and eight females, entering grades 5-9) participated in the campus immersion program. In July 2016, 30 youth participated (18 males, 12 females; entering grades 5-10). Three males entering grade 10 took part in the program in 2016, but were excluded from this study because they were not in middle school; thus there were 27 research participants in 2016. There were nine youth who participated in both years of the program; a total of 40 youth participants are included in this case study $(n=40)$. 
Table 1. Race of Study Participants

\begin{tabular}{|l|c|}
\hline Race & $\begin{array}{c}\text { Number of } \\
\text { participants }\end{array}$ \\
\hline Hispanic or Latino (White) & 4 \\
\hline White, not Hispanic or Latino & 11 \\
\hline Black or African American & 20 \\
\hline Indian or Alaskan Native American & 2 \\
\hline Prefer not to state & 3 \\
\hline Total & 40 \\
\hline
\end{tabular}

Eight of the participants (from five different families) had at least one parent who went to college; the remaining participants were potential first generation college-goers. Family income data were not consistently collected, as most families opted out of reporting income. Youth race is represented in Table 1.

\section{Methodology}

A case study approach was used because it allowed for a focused and in-depth examination of one youth program's influence on youth agency and aspirations. Using this approach yielded insight into youth development processes in a way that can be helpful to youth programs and their staff who might want to replicate program design elements. It also yielded new insight into the relationship between agency and aspirations-setting the stage for future research.

\section{Methods}

Program observations. In both 2015 and 2016, I conducted observations of the youth participants at the campus immersion program. I did not use an observation protocol; instead I took general field notes of what the youth did and said, both during program activities and during unstructured time. When I observed something telling, I conceptualized it (e.g., belonging) and explored that concept further. In the two program years I conducted approximately 45 hours of observations keeping field notes each day of the program. I also had opportunities to spend time with youth at their youth programs and affiliated events. When youth talked about their future or the campus immersion experience to their peers or others, I recorded field notes. 
Program documents. Throughout their time in the campus immersion program youth engaged in experiential learning activities focused on planning for their futures and led by camp counselors. During these activities, youth participants created an educational portfolio. Portfolio pieces, which included vision boards, identity wheels, and goal-oriented action plans, were collected and analyzed as secondary data. The process of creating the program documents (i.e. not just the documents themselves) offered insight into how youth were thinking about their futures. Youth comments, conversations and behaviors were observed and documented in field notes.

Semi-Structured Interviews. Near the end of the program week in the summer of 2016, 18 youth participated in semi-structured interviews about their experience in the program. The intent was to interview all middle school-aged 2016 campus immersion participants, but some youth declined to be interviewed. Interviews were 8 to 20 minutes long and were recorded to ensure accuracy. Interviews began with youth sharing their general thoughts and opinions about campus immersion-stating what they liked, did not like, and why. Follow-up questions prompted youth to describe whether or how certain elements of the program shaped the way they viewed their futures; this incited further discussion based on youth responses. In certain instances, youth were asked to elaborate on what they meant in their program documents.

\section{Analysis}

The theoretical framework of this study served as analytical tool that informed the research design and allowed for an understanding of youth experiences within this program context. All interviews were transcribed. Data were coded from transcripts, program documents, and typed and written field notes. I began with clustering the data into broad parent codes, such as "aspirations" or "obstacles." From this analysis process, I then identified patterned themes within the clusters (e.g., nervousness connected to aspirations), which are presented in the findings section. All data were analyzed both deductively and inductively. Analysis was deductive because it focused on the research question which looked specifically at program effects on aspirations and agency; it was also inductive because unanticipated, patterned findings were discovered in the analysis process that engendered new understandings about youth agency and aspirations. Rigor and trustworthiness of data were ensured through triangulation of methods. 


\section{Findings}

This section summarizes the patterns found in the data and highlights youth voices that are most illustrative of these located patterns. All participants have been assigned pseudonyms to protect their anonymity. Two key themes were identified: making plans for college made youth feel both nervous and prepared, and experiencing campus life fostered a sense of belonging in the youth.

\section{Making Plans Made Youth Feel Nervous but Prepared}

While all youth came to the program with an expressed desire to go to college in the future, my findings indicate that few had thought about it critically until they participated in the program. As Saed, grade 5, said to me in a 2016 interview: "I thought it would be super easy, like just engineering, but it takes really hard work and a lot of years."

The findings further suggest that youth who participated in the campus immersion program gained a more nuanced understanding of what that "hard work" would entail primarily through future-planning activities. For example, Abdulahi, grade 9, came to the program in 2015 insisting that he wanted to be a doctor so he could cure cancer. In fact, a few months before the campus immersion program, he addressed his community at his youth program's stakeholder dinner (which I attended) and shared his aspirations of becoming a doctor; he received a standing ovation after articulating his aspiration. Yet, in a goal-setting activity during campus immersion, he was prompted to think about concrete steps he imagined he would need to take to become a doctor. He relayed to the counselor that he would "work really hard," finish high school, and go to college. The counselor working with him asked him to write down more specific steps. Abdulahi gave a look of consternation; he could not think of anything. With the guidance of a counselor, Abdulahi was able to come up with a more specific plan, such as selecting a course to take when he started high school in the fall. He also learned that doctors specializing in cancer treatment were called oncologists. He was taken aback by his lack of knowledge and said, "I didn't know there were different kinds of doctors." Abdulahi had what most would consider high aspirations-aspirations that were literally applauded by adults-but this experience prompted him to realize an aspiration without a plan was not enough.

Future-planning activities also prompted youth to reflect less on the traditional college application process and more on the socio-cultural, economic, and political contexts that influence their pathways. For instance, many youth were worried about putting an additional 
Supporting Youth Aspirations for Higher Education

financial burden on their families. In 2015, during a program activity, a group of young people discussed whether they would be willing to delay college in order to contribute financially to their family's income. Some youth were adamant that they would need to follow their dreams "no matter what," while others, like Jon, felt obligated to prioritize family needs over his own aspirations saying: "You can't leave your mom!" This was an economic reality that young people faced and the program gave them an opportunity to begin to reconcile the ways in which their values and educational aspirations might be mismatched.

Recognizing barriers and the hard work it required did not deter youth from having aspirations for college; in fact, it seemed that the possession of the aspiration itself that made them willing to take on challenges in order to achieve the future they wanted for themselves. In 2015 Katy, grade 7, insisted that the "tough" stuff was "worth it" when talking to a friend at the program. Abdi, grade 7, reflected on an activity in which youth confronted social obstacles and said, "I learned it's hard to do, but it's for stuff I care about."

Through participating in the program, youth thought critically about what it would take to go to college in the future and planned accordingly. While this appeared to make them nervous, their aspirations were not squelched; youth emerged from the program equipped with plans and felt more prepared.

\section{Experiencing Campus Life Fostered Belonging}

These findings reveal that enjoying life as a college student helped foster a sense of belonging on campus among the participants and helped them develop a college-going identity. Many participants attributed their sense of belonging to the college-aged counselors in the program. Kowsar, who participated in 2015 and 2016, found a niche for herself at the University of Minnesota. As an incoming sixth grader in a 2016 interview she explained, "I think this is my dream school. I really see a lot of role models and there are a lot of majors." When I asked her who the role models were, she named each of the female counselors by name. Jenna, grade 8 , who also participated both years of the program, felt connected to college through the counselors. In a 2016 interview she said, "It just feels a lot more comfortable after this experience thinking about college. People here [referring to counselors] have gone through it and helped me realize what it's really like." Zeinab, grade 8, a 2016 participant stated in a group reflection that physically being on campus helped her feel like she could be successful in college. "I felt that I could live the life of a college student. We all know we wanted to go to college. When we finally set foot on campus, we actually have an idea of what college students 
Supporting Youth Aspirations for Higher Education

do." As a final point, Ayan, a 2016 participant, grade 8, expressed an internalized shift in identity. As I was sitting next to her in the dormitory lounge, she turned to me unprompted and whispered, "I don't know what it is, but I feel like a college student right now."

These findings suggest that having an engaging experience on a college campus and emulating the life of a college student helped youth feel at ease with being on a college campus. This helped them realize college was within their reach and they belonged there in the future.

\section{Discussion}

The Minnesota Urban 4-H campus immersion program offers helpful insight into how youth programs can help youth imagine futures that include higher education and support their capabilities to take action to achieve these futures. A campus immersion program-or a smaller scale program that employs strategies outlined here-can help youth begin to shift how they see themselves and the possibilities for their futures. This can, in turn, activate agency. From a capabilities perspective, it lays the groundwork for young people to make strides toward achieving their aspirations by lessening social constraints and bolstering social supports.

\section{Implications for Practice: Effective Strategies for Youth Workers}

Have youth document plans for their futures. Use activities that help youth rely on social supports and confront or circumvent obstacles.

Why it can work. The findings suggest that programs can serve youth well by helping them confront freedom constraints, practice reflexivity, and consider "creative action" (McNay, 1999; p. 103) to overcome barriers. Appadurai (2004) points out that too often youth are encouraged to desire higher education, but are unaware of the institutional barriers they must face. Through future-planning activities, youth considered, and at times confronted, economic, gender, and social constraints to their freedom to achieve their aspirations. While discussing obstacles to aspiration achievement might be viewed as discouraging, the data suggest the contrary. Activities that address constraints on freedoms related to students' social identity (as discussed by Tikly \& Barrett, 2011) can bring about opportunities for them to be and do what they consider valuable in the future (Sen, 1999). Abdulahi, the aspiring medical doctor, for example, had a valued future desire and emotional support from his community, but he had little else in his social arrangements to guide his actions toward actual achievement. His lack of preparedness unnerved him, but this awareness in his middle years prompted action to make a 
plan for his future that could help him avoid what Bourdieu (1984) described as "blighted hope" for his future (p.150) when it is time to apply for college.

Ways to do it (through experiential learning activities)

- Have youth create a vision board in which they visually depict the futures they hope and desire.

- Have youth draw a roadmap of their educational pathways with symbolic roadblocks and supports/bridges.

- Have youth write a personal statement for a mock college application in which they describe confronting adversity to reach a goal.

- Always reflect on learning after doing an activity.

- Give youth opportunities to share the educational plans with family or community members.

Avoid boosting aspirations; instead, foster youths' abilities to imagine themselves as college students.

Why it can work. Youth in this study already possessed an expressed desire to go college in the future. What changed in the program was that they began to develop a college-going identity through belonging. Rather than college being an abstract future possibility only experienced through representation, it became a concrete experience internalized through firsthand involvement in college life. An immersion program can serve as a place where youth imagine themselves as college students and situate their aspirations in something real. Some participants were explicit about how these experiences put them at ease with going to college. Others, like Ayan, revealed a college-going identity that seemed subtly instilled into her subconscious. This is at the heart of the habitus-an internalized identity that will guide action toward aspiration achievement.

\section{Ways to do it}

- Take youth on campus tours that help young people know what it's like to find classrooms, places to study, and places to relax or socialize. (Avoid official admission office tours; they don't emulate student life.)

- Connect youth with student groups on a campus to learn about non-academic activities in which they can participate or to meet students who share their social identities. 
- Schedule "free time" on campus allowing youth to play games or "hang out" in dormitory lounges or on the campus lawns (e.g., pick-up soccer, listening to music).

- Recruit/hire/engage current college students to have lead roles.

- Train them in youth development best practices.

- Emphasize their role as mentors who represent youths' possible futures.

- Plan a time for a roundtable or panel for the counselors to share their college experiences and to answer questions with and for the youth participants.

- Work with a university's or college's conference and event planning team to reserve typical student locations such as: dorm rooms, cafeterias, game rooms, or classrooms

\section{Limitations}

This study, while small in scope, offered insight into how a youth program designed to engage marginalized youth in college life affects aspirations for higher education and youth agency. Findings were not intended to be generalizable. Youth participants were members of youth programs from one urban area in a Midwestern state and they experienced only one Midwest public university. This study captures youth at one moment in time during a particular stage of their development. Time will tell how youth participants continue to enact agency toward aspiration achievement, how aspirations will change, or if youth eventually matriculate in postsecondary institutions. Of course, circumstances outside of the program-such as family and peer influences or school and teaching quality-also influence their educational trajectories.

\section{Next Steps}

This research, as well as the research of others', indicates that an aspiration for higher education is not a commodity to be possessed, but an asset to be developed with critical reflection so that young people can take action to achieve it. The findings call attention to social supports youth programs can offer, such as strategies for helping youth develop a sense of belonging on a college campus and helping youth make plans for their futures that include addressing barriers and locating and utilizing social supports. Practitioners can incorporate these findings in program design efforts geared toward preparing young people for higher education. Future research that explores how youth continue to pursue higher education will be critical to understanding how youth programs support youth agency related to their aspirations in the long-term. Additionally, the nature of the mentorship roles counselors offer youth-particularly around fostering a sense of belonging for youth in higher education-ought to be explored in future research. 


\section{Acknowledgements}

Research reported in this article was supported by CYFAR program with funds from the National Institute of Food and Agriculture. This research came as part of a 5-year grant under award number $1305 S 32461$ and led by principal investigator Jennifer Skuza.

\section{References}

Alkire, S. (2005). Capability and functionings: Definition \& justification. Retrieved from https://hdca.org/publication/capability-and-functionings-definition-justification

Appadurai, A. (2004). The capacity to aspire. In Rao, V., and M. Walton (Eds.), Culture and public action (pp. 59-84). Stanford, CA: Stanford University Press.

Balfanz, R. (2009). Putting middle grades students on the graduation path. Policy and practice brief. Bourdieu, P. (1977). Cultural reproduction and social reproduction. In J. Karabel \& A. Halsey (Eds.), Power and ideology in education (pp. 487-510). New York: Oxford University.

Bourdieu, P. (1984). Distinction: A social critique of the judgement of taste. Boston, MA: Harvard University Press.

Bourdieu, P. (1990). The logic of practice. Stanford CA: Stanford University Press.

Conradie, I., \& Robeyns, I. (2013). Aspirations and human development interventions. Journal of Human Development and Capabilities, 14(4), 559-580.

DeJaeghere, J., \& Lee, S. K. (2011). What matters for marginalized girls and boys in Bangladesh: A capabilities approach for understanding educational well-being and empowerment. Research in Comparative and International Education, 6(1), 27-42.

DeJaeghere, J. (2018). Girls' educational aspirations and agency: imagining alternative futures through schooling in a low-resourced Tanzanian community. Critical Studies in Education, 1-19.

Gale, T., \& Parker, S. (2015). Calculating student aspiration: Bourdieu, spatiality and the politics of recognition. Cambridge journal of education, 45(1), 81-96.

Eberle, F. (2010). Why STEM education is important. InTech. Retrieved from http://www.isa.org/InTechTemplate.cfm?template=/ContentManagement/ContentDi play. $\mathrm{cfm} \&$ ContentID $=83593$

Fry, (2010). Minorities and the recession-era college enrollment boom. Retrieved from http://www.pewsocialtrends.org/files/2010/11/757-college-enrollment.pdf

Gale, T., \& Parker, S. (2015). Calculating student aspiration: Bourdieu, spatiality and the politics of recognition. Cambridge Journal of Education, 45(1), 81-96. 
Kao, G., \& Tienda, M. (1998). Educational aspirations of minority youth. American journal of education, 106(3), 349-384.

McLeod, J. (2005). Feminists re-reading Bourdieu: Old debates and new questions about gender habitus and gender change. Theory and research in education, 3(1), 11-30.

McLeod, J. (2012). Vulnerability and the neo-liberal youth citizen: A view from Australia. Comparative Education, 48(1), 11-26.

McNay, L. (1999). Gender, habitus and the field Pierre Bourdieu and the limits of reflexivity. Theory, culture \& society, 16(1), 95-117.

National Research Council. (2002). Community programs to promote youth development. Washington, DC: National Academies Press.

Roderick, M., Nagaoka, J., \& Coca, V. (2009). College readiness for all: The challenge for urban high schools. The future of children, 19(1), 185-210.

Sen, A. (1999). Development as Freedom. New York: Oxford University Press.

Tikly, L., \& Barrett, A. M. (2011). Social justice, capabilities and the quality of education in low income countries. International Journal of Educational Development, 31(1), 3-14. doi:10.1016/j.ijedudev.2010.06.001

UNESCO (2010) Education for all global monitoring report: Reaching the marginalized. Oxford, UK: Oxford University Press.

Unterhalter, E., Vaughan, R., \& Walker, M. (2007). The capability approach and education. Prospero, 13(3), 13.

U.S. Department of Education. (2014). The condition of education 2014, Retrieved from https://nces.ed.gov/pubs2014/2014083.pdf

Walker, M. (2016). Aspirations and equality in higher education: gender in a South African university. Cambridge journal of education, 1-17. 